\title{
Uranium possibilities at El Gilf El Kiber area, Southwestern part of the Western Desert, Egypt.
}

\author{
Atef A.M.1, El-Arabi H. Sh.2 and Tamer M.R.1* \\ 1 Nuclear Materials Authority, Cairo, Egypt. \\ 2 Faculty of Science, Suez Canal University, Ismailia, Egypt.
}

\begin{abstract}
El Gilf El Kiber area is located in the Southwestern part of the western desert, Egypt which is delineated by longitudes $25^{\circ}$ to $26^{\circ} 30^{\prime}$ E and latitudes $22^{\circ}$ to $23^{\circ} 20^{\prime} \mathrm{N}$, at the border between Egypt with Libya and Sudan. It is considered as one of the most important promising areas of reclamation and urban growth. The area approximately covers $16600 \mathrm{Km} 2$. The rock units in the study area can be arranged in ages from Precambrian (mainly granite) to Quaternary (mainly sand).

Airborne geophysical surveys (gamma-ray spectrometry) data was collected over El Gilf El Kiber area by the airborne geophysics department of the Nuclear Materials Authority of Egypt. This data was analyzed and processed to produce maps for the concentration of radioactive elements ( $U$, Th and K). Moreover, the identification and significance of uranium anomalies were also studied.

The high radioactive anomalies were associated with the granitic rocks and have NNE-SSW direction. Sand sheets have also high radiation in that direction because of the leaching of uranium from the surrounding outcropping. Promising sites for uranium mineralization have been detected for further ground confirmation detailed studies.
\end{abstract}

Keywords: Uranium; Airborne gamma ray spectrometry; Radioactivity; Western Desert; Egypt.

\section{INTRODUCTION}

The study area is located in the Southwestern part of the western desert of Egypt which is delineated by longitudes $25^{\circ}$ to $26^{\circ} 30^{\prime} \mathrm{E}$ and latitudes $22^{\circ}$ to $23^{\circ} 20^{\prime} \mathrm{N}$, at the border between Egypt with Libya and Sudan Fig (1), covering about $16,600 \mathrm{Km} 2$.

Geophysical data are unlike most remotely sensing data, in that they are not gathered as continuous images. Instead, measurements of various fields and physical properties of surface and subsurface materials are made either at isolated points on the surface or along lines as a more or less continuous one-dimensional record (Ismail, 1999). Accordingly, geophysical measurements are usually considered to be samples of continuous functions. They can be used to generate a grid of discrete estimates of that function by interpolation from which contour maps or images can be produced (Broome, 1990).

Gamma-ray spectrometry provides a method for estimating uranium, thorium and potassium concentrations in the near surface materials. Different rock types have different characteristic concentrations of radioelements. Thus, the concentrations, which are calculated from gamma-ray spectrometric data, could be used to identify zones of consistent lithology and contacts between contrasting lithologies (Ismail, 1999).The surface concentrations of the radioelements potassium, uranium and thorium can be quantified by measurements of intensities of gamma ray radiation emitted by their respective radioisotopes 40K, 214Bi and $208 \mathrm{Tl}$ respectively. Airborne gamma-ray spectrometry can be of direct assistance to exploration for many commodities, most obviously for $\mathrm{U}$ and $\mathrm{Th}$, but commonly also for $\mathrm{Sn}, \mathrm{W}, \mathrm{Nb}$, and $\mathrm{Zr}$. Less often, but of importance in specific circumstances, radiometric anomalies can point to $\mathrm{Au}, \mathrm{Ag}, \mathrm{Hg}, \mathrm{Co}, \mathrm{Ni}, \mathrm{Bi}, \mathrm{Cu}, \mathrm{Mo}, \mathrm{Pb}$ and $\mathrm{Zn}$ mineralization, either because one or more of the radioelement is an associated trace constituent or because the mineralizing process has changed the radioelement ratios in the surrounding environment (Darnley and Ford, 1989).

In the present study, airborne gamma ray spectrometric data has been collected over the El Gilf El Kiber area in the southwestern part of the western desert of Egypt by the Nuclear Material Authority (NMA) and interpreted in an attempt to evaluate the distribution of the radioactive minerals in the different rock units. Moreover, it has been tried to locate promising sites for uranium occurrences.

\section{[1]. II. Geologic Setting}

The study area contains the following rock units, arranged from the oldest to the youngest according to Conoco, 1987 (Fig.2):

1. Precambrian to Cambrian intrusive rocks:

a) Granoblastite Formation, Anatexite formation and Granitoids,

b) Grey-green granitoids and red granite, 
c) Normal granite,

d) Gabbro.

2. Gabal Babein ring complex

3. Carboniferous and Cretaceous sediments (mainly sandstone)

4. Tertiary volcanic rocks (trachyte and basalt)

5. Quaternary deposits (sand sheet, and sand dunes).

The exposed rocks are dissected by three major faults which have NE-SW, NW-SE and ENE-WSW directions. The most important of them is that recorded in the southeastern part, which exhibits dextral slip sense of movement, proved by the remarkable displacement of the axial trace of the previously mentioned major NWSE overturned fold (Abdel Fattah, 2005). This is further emphasized by the fact that these metamorphic assemblages are intruded by the Late Pan-African syenitic ring complex. The oldest rocks of Archaean age, which are outcropped at Gebel Uweinat, at the extreme southwestern corner of Egypt, correlate with the Tibesti massif of southern Libya. Since the basement rocks are the oldest rocks in Egypt, they are expected to record all tectonic events from early Precambrian to the present. The Pan-African structures of the Tibesti area in Libya have a significantly regular, northeasterly trend extending northward to Gebel Uweinat microcraton and further beneath the Western Desert. The Nubian trend and the Tibesti trend seem to intersect along a major structural discontinuity across Egypt, (Richter; 1986, Richter and Schandelmeier, 1990).

The basement rocks of the study area were referred to as a peneplain composed mainly of anatexite intruded by granitoid rocks, (Richter; 1986, Richter and Schandelmeier 1990).

Gabal Nazar or the "Peneplain" is made up of large exposures of granite plutons intruding into Precambrian gneisses with clear sharp contacts. Age determination of the intrusive rocks of this unit indicates that they belong to the Pan-African progeny (Sultan et al., 1996). Richter (1986) and Richter and Schandelmeier (1990) classified the rocks in the northwestern Sudan and southwestern Egypt into four groups according to their geological setting, macroscopic appearance and bulk composition which are: (1) grey-green calc-alkaline granitoids, (2) red alkaline granites, (3) porphyritic calc-alkaline granitoids, and (4) alkaline syenite to alkaline granitic ring complexes.

\section{Data Used}

The spectrometric data acquisition was carried out by the Airborne Geophysical Department (AGD) in the Nuclear Materials Authority (NMA) of Egypt. The Spectrometric survey has been conducted over traverse lines directed N-S (0o-180o) and tie lines directed E-W (90o-270 o). Flight line spacing was $2000 \mathrm{~m}$ and the tie line spacing was $10000 \mathrm{~m}$ Fig (3). Survey data has been acquired in April 2011 in the most efficient manner.

The airborne gamma-ray spectrometer records 256 channels of spectral data in the range $0-3 \mathrm{MeV}$, and uses self stabilizing to minimize spectral drift. This spectrometer monitors one of the prominent photopeaks to automatically adjust photomultiplier tube gains for each crystal to ensure spectral stability.

Table (1) indicates that the spectrometer normally records three additional windows to monitor $40 \mathrm{~K}$ gamma rays at $1460 \mathrm{keV}, 214 \mathrm{Bi}$ gamma rays at $1760 \mathrm{keV}$ from the uranium decay series, and $208 \mathrm{Tl}$ gamma rays at $2615 \mathrm{keV}$ from the thorium decay series. A total count window is also recorded to monitor overall radioactivity levels at $410 \mathrm{KeV}$ to $2810 \mathrm{KeV}$. The detector count rates, due to cosmic radiation, increase exponentially with height above mean sea level. A cosmic ray window which records all incident particles above $3 \mathrm{MeV}$ is commonly used to monitor this increase (Grasty and Minty, 1995).

Table (1) Standard windows for natural radioelement mapping (After Grasty and Minty, 1995)

\begin{tabular}{|c|c|c|c|}
\hline Window name & Isotope used & $\begin{array}{c}\text { Gamma-ray energy } \\
(\mathrm{KeV})\end{array}$ & $\begin{array}{c}\text { Energy window } \\
(\mathrm{KeV})\end{array}$ \\
\hline Potassium & ${ }^{40} \mathrm{~K}$ & 1460 & $1370-1570$ \\
\hline Uranium & ${ }^{214} \mathrm{Bi}$ & 1760 & $1660-1860$ \\
\hline Thorium & ${ }^{208} \mathrm{Tl}$ & 2615 & $2410-2810$ \\
\hline Total Count & - & - & $410-2810$ \\
\hline Cosmic & - & - & $3000-\infty$ \\
\hline
\end{tabular}




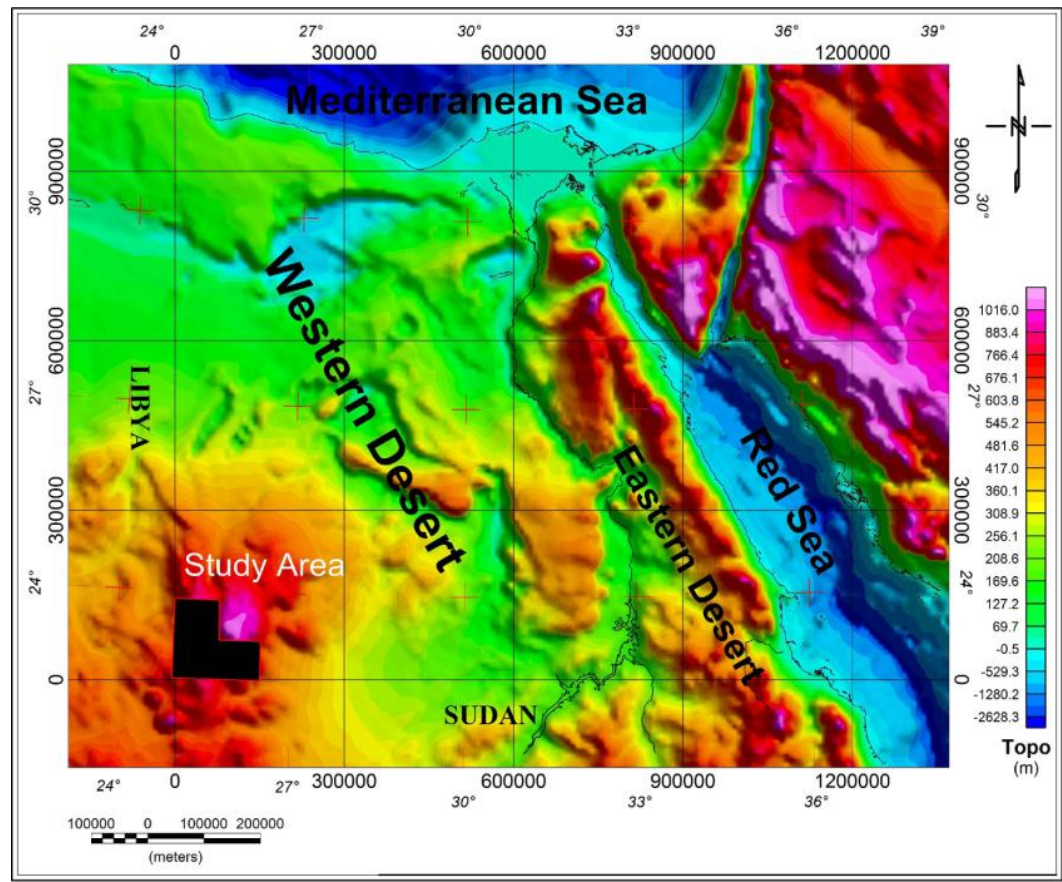

Fig (1) Topographic Map of Egypt showing the location of El Gilf El Kebir area, Southwestern part, Western Desert, Egypt.

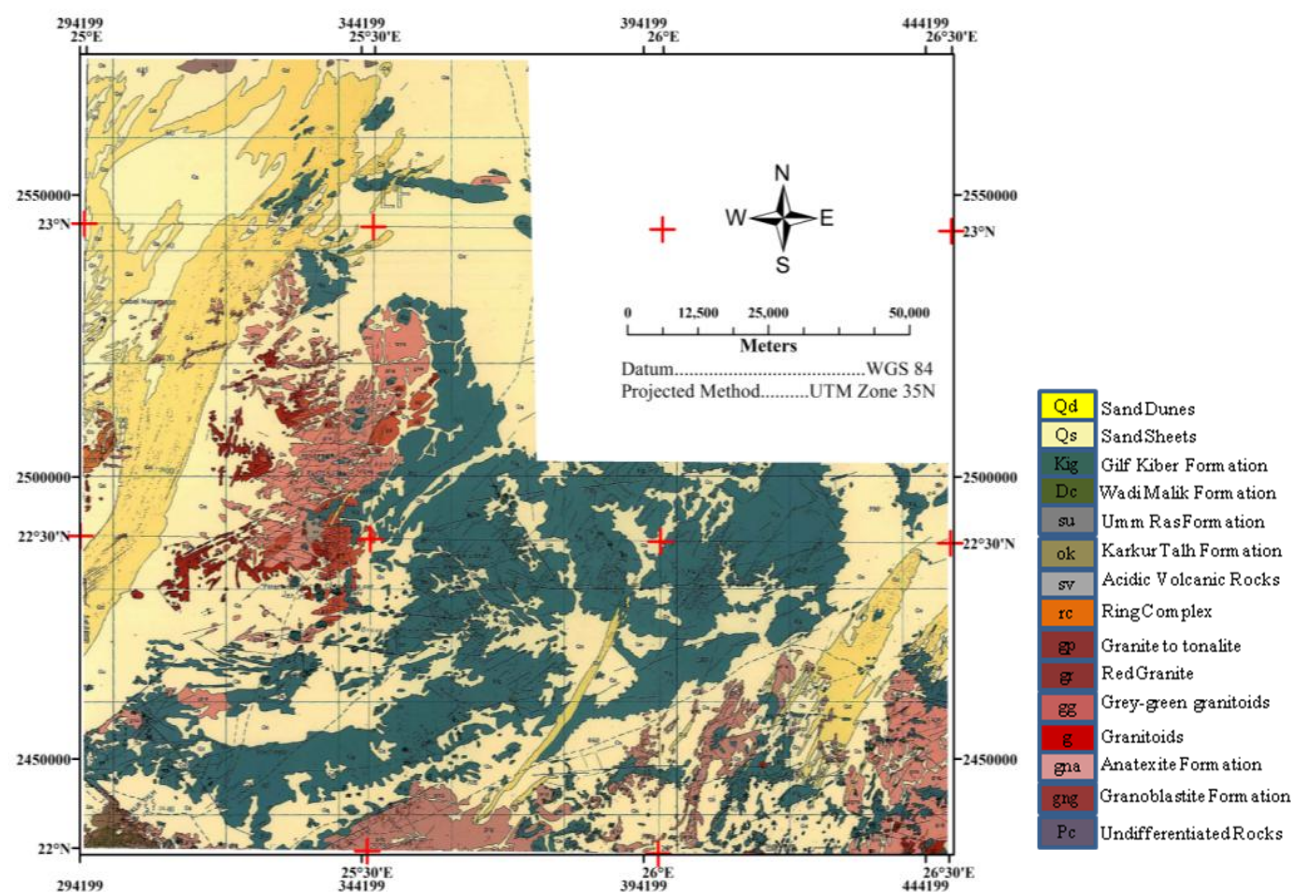

Fig (2) Geologic Map of El Gilf El Kiber area, Southwest, Western Desert, Egypt.

(After Conoco, 1987) 


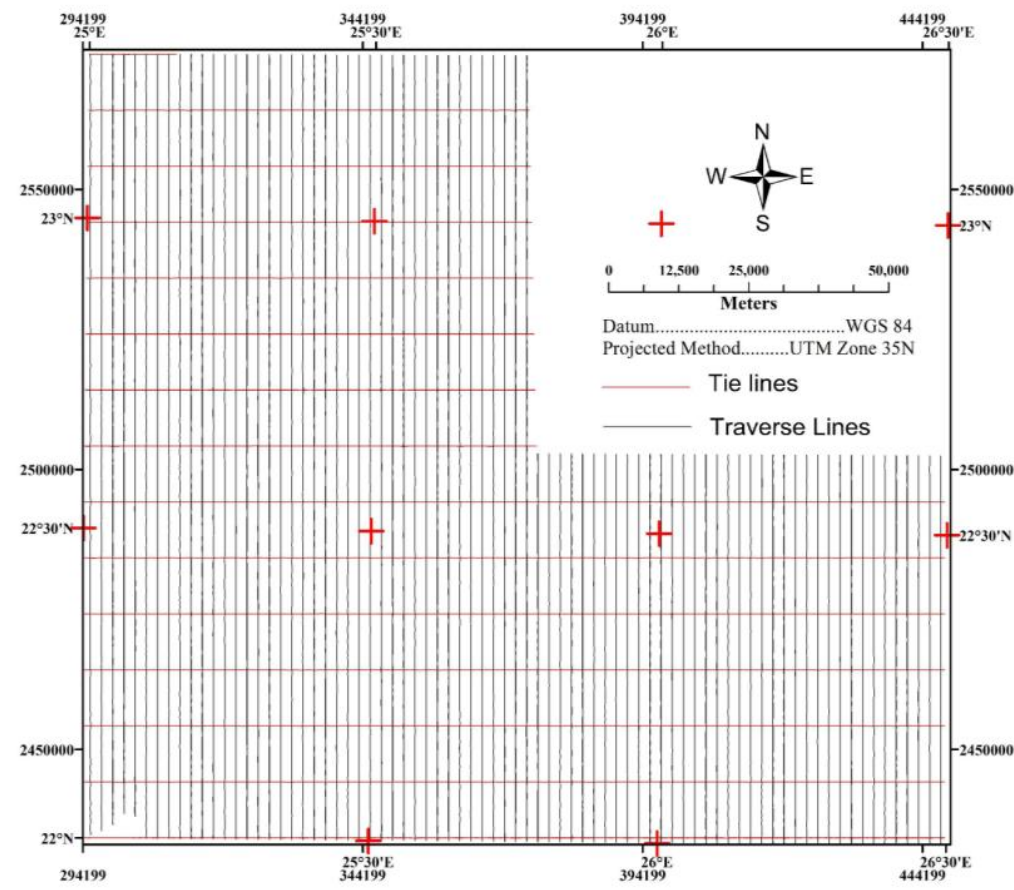

Fig (3) Map showing Flight lines in El Gilf El Kebir area, Southwest, Western Desert, Egypt, (after NMA, 2011).

The gamma ray spectrometric data was corrected and processed to remove the effects of Radon decay products in the air, the radioactivity of the aircraft and its equipment and the high energy cosmic ray particles that interact with the air.

The spectrometric data has been converted to an image format and gridded to $500 \mathrm{~m}$ interval using cubic-spline interpolation. The gridding process acts as a spatial filter that reduces the spatial resolution of the data.

\section{[2]. IV. Interpretation of Gamma Ray Spectrometric Data}

The four parameters namely: total-count of the gamma radiation (TC, in $\mu \mathrm{R} / \mathrm{h}$ ), absolute concentrations of the three radioelements: equivalent uranium (eU, in $\mathrm{ppm}$ ), equivalent thorium (eTh, in $\mathrm{ppm}$ ) and potassium $(\mathrm{K}$, in \%), are represented by Figure 4 (A, B, C and D) respectively and showing the relative variation of the gamma radiation in the study area. The three main radiometric element concentrations mainly reflect the lateral variation of surface elemental concentration of different rocks and soil types. The major trend that could be traced from the four radiometric maps is the NNE-SSW trend.

The studied area was qualitatively interpreted into three zones according to the variation of gamma-ray spectrometric values which are: The lowest level (level 1 bright blue to green color) is encountered in the four radiometric maps and conjugated with the part of the area covered with sand dunes and sand sheets. It is more or less having the same feature of no radiometric effect. The intermediate level (level 2 green to yellow color) is spreaded all over the area and correlated with the distribution of both Carboniferous and Cretaceous sediments (mainly sandstone and sand sheets) with granites. Whereas, the highest level (level 3 red to magenta color) is associated with the basement rocks. This level, in all maps, is related to the areas of exposed and intrusions of granitic rocks and Ring complex.

The observed radioelement composite images (Fig. 5A) composed of eU in red, eTh in green and $\mathrm{K}$ in blue show a fairly close spatial correlation with the geological map of (Fig. 2). The high values (bright color) are strongly correlated with granites and Ring complex and the surrounding rocks.

These rocks show a strong spatial correlation with the anomalous zones of eU, eTh, and K. Whereas, the low concentrations of eU, eTh and K show dark areas (Fig. 5A) which represent the areas covered with the Quaternary deposits. These zones display a sharp color contrast with the bright colored zones (granitiod rocks) which reflects the great difference in the radioelement content of the two zones. 


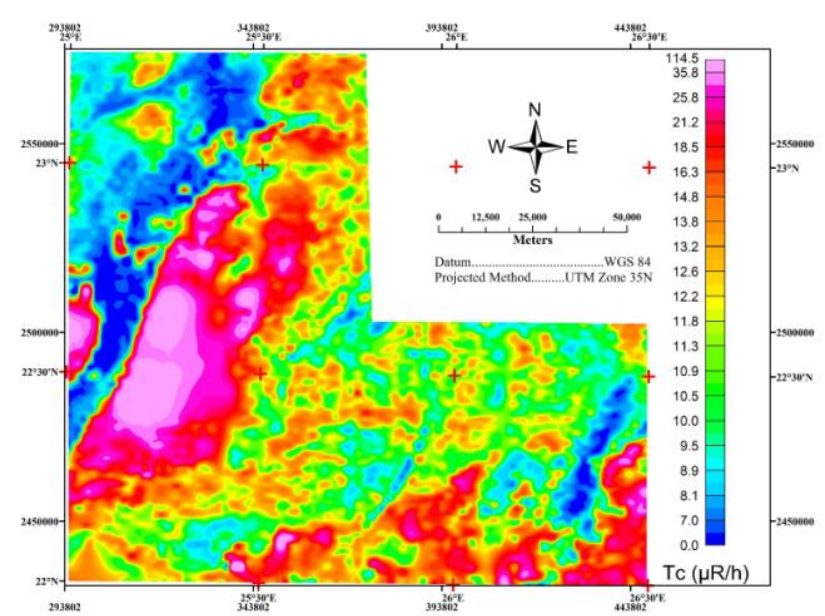

A

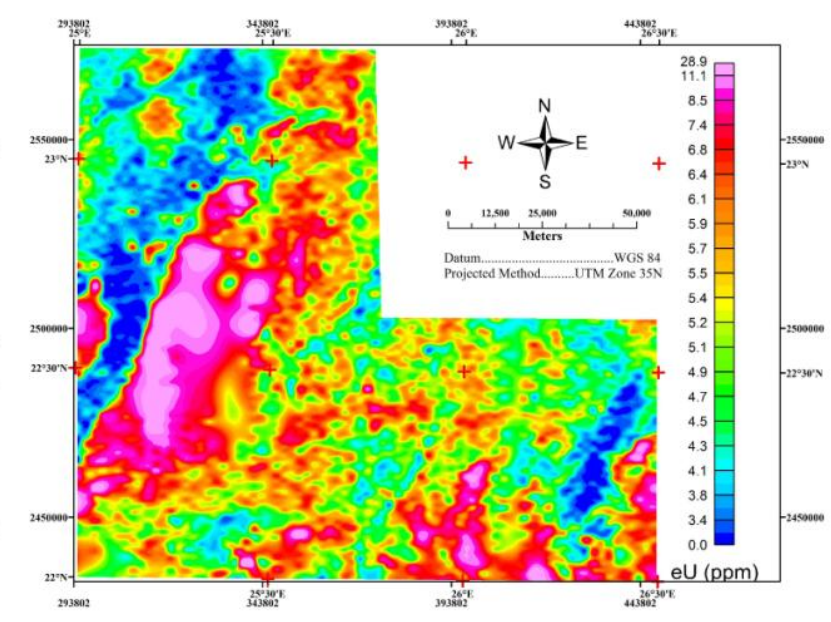

B

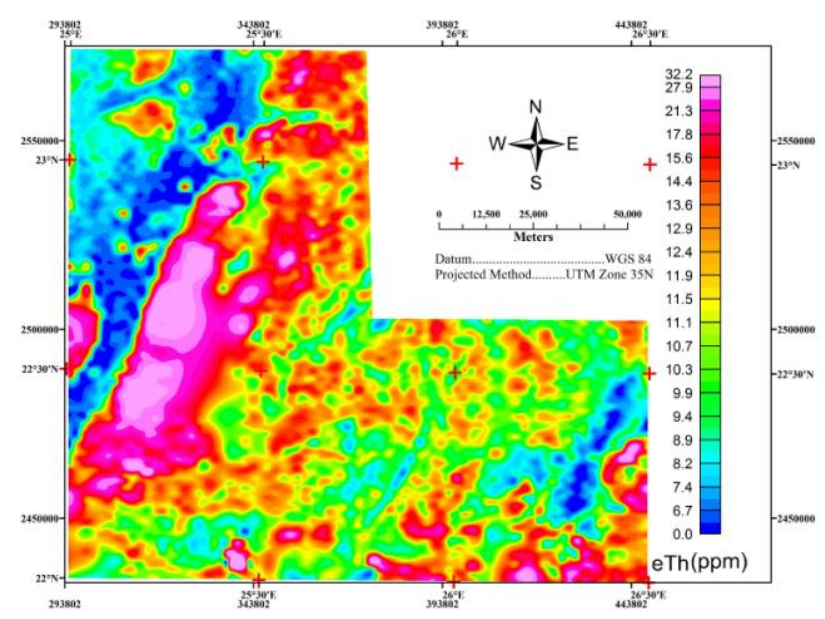

C

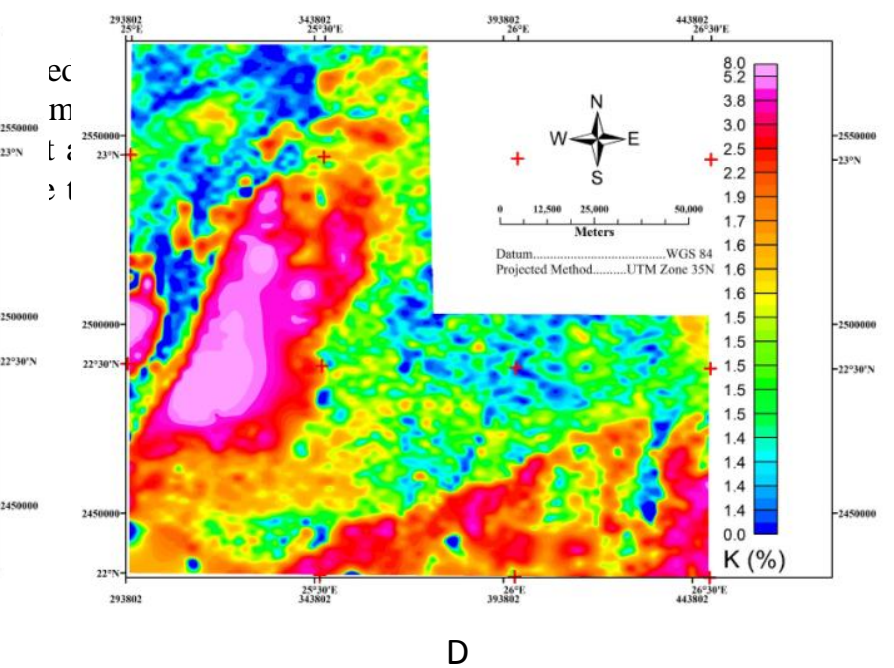

D

Fig (4) Gamma ray spectrometric maps of El Gilf El Kiber area

A) Total Count, B) Equivalent Uranium, C) Equivalent Thorium and D) Potassium 
The eTh composite image composed of eTh in red, eTh/eU in green and eTh/K in blue (Fig. 5C) emphasizes the relative distribution of thorium and highlights areas of thorium enrichment. The white bright color on this image map is a good pointer to areas where thorium has been preferentially enriched relative to both potassium and uranium. These areas are mainly associated with some portions of granites in the area. This thorium-enriched granite represents a good prospect for deposits of heavy mineral placers and rare-earth elements (Ali, 2009).

The potassium composite image composed of $\mathrm{K}$ in red, $\mathrm{K} / \mathrm{eU}$ in green and $\mathrm{K} / \mathrm{eTh}$ in blue (Fig. 5D) shows the overall spatial distribution of relative potassium concentrations. Anomalous locations can be distinguished on the potassium composite map by their white bright color (high values).

The major objective of the interpretation of the airborne gamma-ray spectrometric survey data is to define the probable locations and boundaries of potential uraniferous provinces in which the rocks and soils are preferentially enriched in uranium. This could be given by the following expression:

\section{$\mathrm{eU}>\mathrm{X}+3 \mathrm{~S}$}

Where: " $\mathrm{X}$ " is the arithmetic mean and " $\mathrm{S}$ " is the standard deviation

The uranium anomaly map (Fig. 6) shows six sites of statistically high eU abundance. They are associated with high eU/eTh and eU/K ratio values. These anomalous sites are considered to be exploration targets of first priority for ground geophysical, geological and geochemical follow-up. The summary of these results are collected in the following table, (Table 2).

Table (2): possible uranium anomalies distribution in (ppm) in El Gilf El Kiber area.

\begin{tabular}{|c|c|c|c|c|c|}
\hline & Min & Max & Mean & Stander Division & X+3S \\
\hline Granites \& Surrounded Sand Sheets & 3.69 & 28.9 & 7 & 2 & 13 \\
\hline Ring Complex & 2 & 11.5 & 6.9 & 1.9 & 7.04 \\
\hline Umm Ras formation & 4 & 7 & 5.3 & 0.58 & 5.69 \\
\hline Sand Sheets & 3.05 & 6.7 & 4.4 & 0.43 & 5.5308 \\
\hline Gil Kiber formation & 3.3 & 10.2 & 5.34 & 0.0636 & 4.98 \\
\hline
\end{tabular}

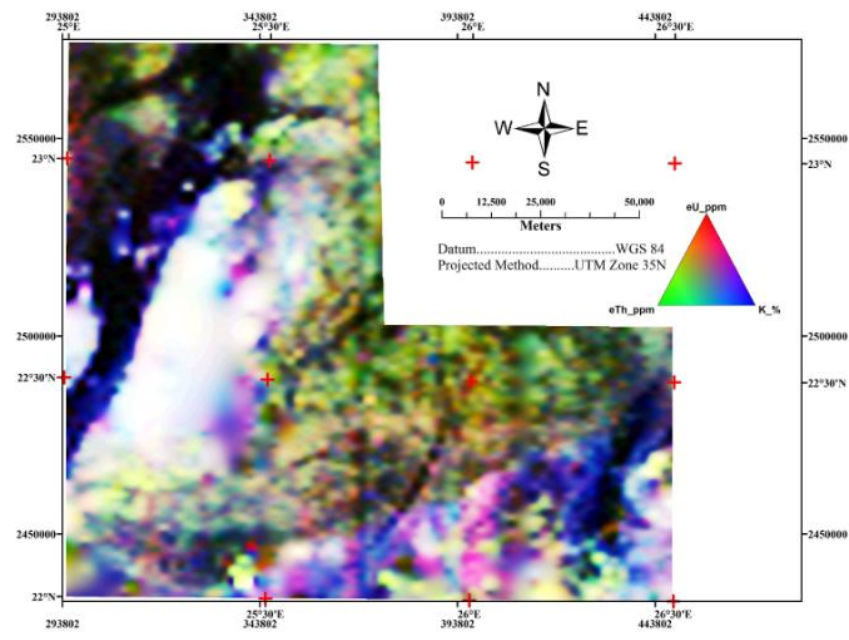

A

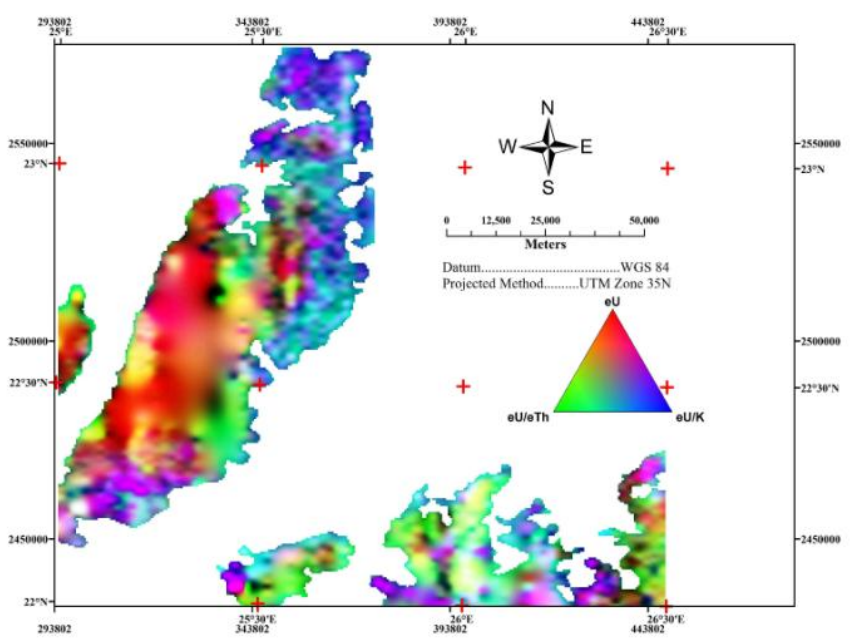

B 


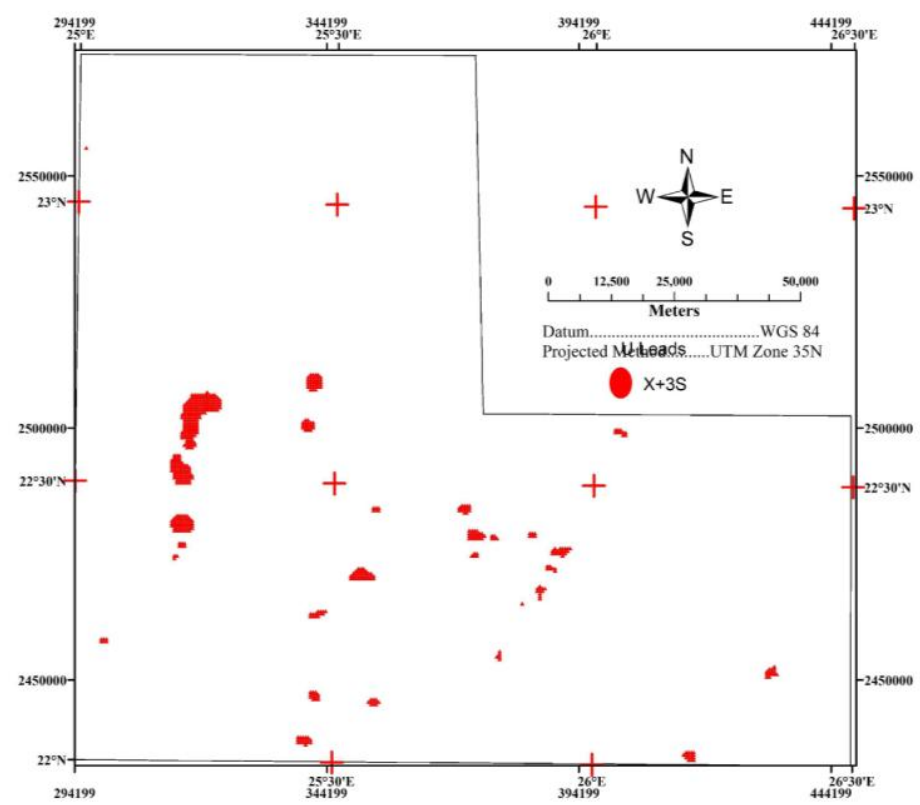

Fig (6) Possible locations of uranium anomalies, El Gilf El Kiber area, South Western Desert, Egypt.

\section{[3]. V. Conclusions}

The Airborne gamma-ray spectrometry is a passive remote sensing technique that measures the natural emission of gamma-ray radiation from the upper $30 \mathrm{~cm}$ of the earth's surface. The principle gamma-ray emitting isotopes used in airborne geophysical surveys are $40 \mathrm{~K}$, and the $232 \mathrm{Th}$ and $238 \mathrm{U}$ decay series. These are used to estimate potassium, thorium and uranium abundances, respectively. Gamma rays emitted from the earth's surface mainly relate to the mineralogy and geochemistry of the bedrock and weathered materials (e.g. soils, saprolite, alluvial and colluvial sediments). Gamma-ray imagery can thus be regarded as a surface geochemical map showing the distribution of the radionuclides in rocks, regolith and soil.

At El-Gilf El-Kiber area, in the western desert of Egypt, airborne gamma ray spectrometric survey has been carried out by the Nuclear Materials Authority of Egypt (NMA) in an attempt to map the surface distribution of the radioactive minerals ( $\mathrm{U}, \mathrm{Th}$ and $\mathrm{K} 40$ ) and to find out any possible anomalous zones that could be studied in details. Also, this study tried to find any relation between the distribution of the radioactive minerals and the prevailing rock types.

Processing and interpretation of the airborne spectrometric data, in the light of the different rock types in the study area, concluded that high radiation is associated with the granitic rocks even if there are covered by thin sand sheets and wadi deposits. Most of the radiation phenomena are due to uranium minerals and have NNE-SSW trend. Comparing this uranium sites with the geological map of the study area, it was found that these sites are located between three systems of structure lineaments. It is highly recommended to study these sites, in details, to evaluate the occurrence of the uranium mineralization.

\section{References}

[4]. Abdel Fattah, M. F., (2005) Petrological and Geochemical Studies on the Basement Rocks of Northeast Gabal Uweinat area, Western Desert, Egypt. Ph.D thesis, Suez Canal University, Ismailia, Egypt.

[5]. Ali M.M., 2009: Acquisition, processing and interpretation of airborne magnetic and gamma-ray spectrometry survey data of elkharga area, central Western Desert, Egypt, M.Bc. Thesis, Menoufiya university, Menoufia, Egypt.

[6]. Broome, H. J., 1990, Generation and interpretation of geophysical images with examples from the Rae Provinces, northwestern Canada shield. Geophysics, 55/8, 977-997.

[7]. Conoco Coral and EGPC (1987): Geological Map of Egypt, NF-36 NE Berince, Scale 1: 500,000. Geological survey of Egypt.

[8]. Darnley, A. G., Ford, K. L., 1989: Regional airborne gamma-ray surveys, a review. Proceedings of Exploration, 87; Third Decennial Inter-national Conference on Geophysical and Geochemical Exploration for Minerals and Groundwater, edited by G. D. Garland, Ontario, Canada, Geol. Sur., Can., Special V.3 pp 229-240.

[9]. Grasty, R. L., and Minty, B. R. S., 1995: A guide to the technical specifications for airborne gamma-ray survey, Australian geophysical survey organization, record 1995/60, 89 p.

[10]. Ismail, A. A. M., 1999: Evaluation of digitally-processed aerial gamma-ray spectrometric and magnetic data for geologic mapping, mineral exploration and monitoring of environmental radioactivity, abu-had area, central eastern desert, Egypt,Ph.D. Ain Shams university. 
[11]. Nuclear Materials Authority (NMA), 2011: High resolution airborne gamma ray spectrometric survey data over El Gelf El Kebier area, south west western desert, Egypt. Internal report.

[12]. Richter, A. and Schandelmeier, H., 1990: Precambrian basement inheres of Western Desert, Geology, petrology and structural evolution. In: R. Said (Ed.). Geology of Egypt. A.A, Bulkhama, 1990 , P.185-200.

[13]. Richter, A., 1986: Geologie der metamorphen und magmatischen Gesteine In Gebiet Zwischen Gebel Uweinat und Gebel Kamel,sw Agypten NW Sudan. Berl. Geowiss. Agh. 73, (A, pp.1-201.

[14]. Sultan, M., El Alfy, Z. and Tucker, R., (1996): U-Pb (Zircon) age from the Uweinat area. Geol. Sun, Centennial. Cairo (Abstract). 